\title{
The Use of Wearable Inertial Motion Sensors in Human Lower Limb Biomechanics Studies: A Systematic Review
}

\section{Daniel Tik-Pui Fong ${ }^{1,2, *}$ and Yue-Yan Chan ${ }^{1,2,3}$}

1 Department of Orthopaedics and Traumatology, Prince of Wales Hospital, Faculty of Medicine, The Chinese University of Hong Kong, Hong Kong, China

2 The Hong Kong Jockey Club Sports Medicine and Health Sciences Centre, Faculty of Medicine, The Chinese University of Hong Kong, Hong Kong, China

3 Department of Orthopaedics and Traumatology, Alice Ho Miu Ling Nethersole Hospital, Hong Kong, China

* Author to whom correspondence should be addressed; E-Mail: dfong@ ort.cuhk.edu.hk; Tel.: +852-2632-3535; Fax: +852-2646-3020.

Received: 1 November 2010; in revised form: 1 December 2010 / Accepted: 14 December 2010 / Published: 16 December 2010

\begin{abstract}
Wearable motion sensors consisting of accelerometers, gyroscopes and magnetic sensors are readily available nowadays. The small size and low production costs of motion sensors make them a very good tool for human motions analysis. However, data processing and accuracy of the collected data are important issues for research purposes. In this paper, we aim to review the literature related to usage of inertial sensors in human lower limb biomechanics studies. A systematic search was done in the following search engines: ISI Web of Knowledge, Medline, SportDiscus and IEEE Xplore. Thirty nine full papers and conference abstracts with related topics were included in this review. The type of sensor involved, data collection methods, study design, validation methods and its applications were reviewed.
\end{abstract}

Keywords: inertial sensors; accelerometers; gyroscopes; magnetic sensors; joint kinematics; motion analysis 


\section{Introduction}

Wearable inertial motion sensors consisting of accelerometers, gyroscopes and magnetic sensors are readily available nowadays [1]. Some companies, such as XSens Technologies (The Netherlands) and Innalabs (Russia) provide inertial motion sensor solutions. They are highly transportable, no stationary units, such as receivers and cameras are needed for data collection, therefore can be used outside laboratory conditions [2]. Inertial motion sensor is a good choice for human biomechanics studies because it is highly transportable, low cost and consumes low power during operation.

Accelerometers have been adopted in human joint kinematics studies since 1990s. Willemsen [3] and Heyn [4] applied uniaxial accelerometers on aluminum strips, which were then attached on the foot, shank, thigh and pelvis of subjects by Velcro straps. In their studies, four accelerometers on rigid metal plates were needed on each segment, otherwise they would have had to numerically integrate twice the angular acceleration of the segment to get the joint angle [5]. Therefore a total of eight accelerometers were needed to estimate joint kinematics. Only uniaxial joint kinematics could be obtained. Also, in both studies, leg segments were assumed to be rigid bodies, and the joints were single axis hinge joint. These simplified joint models were good for simple motion analysis, for example two dimensional single joint motion analysis.

Simplified systems were developed in 2000s. Data from accelerometers and gyroscope could be used to estimate orientation relative to an inertial frame [1]. Although relative orientation could be estimated by integration of data from gyroscope, errors would accumulate by this method, which caused distortion and drift errors. Accelerometer can be used to compensate the drift of the gyroscope about the axes of the horizontal plane, while magnetic sensor which located orientation by earth's magnetic field was adopted to solve this drift problem about the vertical axis [6]. However, inside reinforced-concrete-covered buildings, the magnetic field on the earth was always perturbated. Further development of high accuracy three dimensional relative orientations was developed by Favre and his colleagues [7]. Favre and his colleagues integrated angular velocity data obtained from gyroscopes, and then corrected the angle estimation based on inclination data from accelerometers gathered during rest or constant velocity motion period. Known joint anatomical constraints were also considered for better estimation in a later study [8]. Static calibration in a defined position was still needed. Cooper [1] and his colleagues extended the measurements in dynamic activities. However, Cooper's studies only involved a simplified model of a single hinge knee joint, further extension of the technique was needed for three dimensional measurements.

\section{Methods}

The research method was graphically displayed in Figure 1 for better understanding of the procedure. Systematic literature search of Medline (from 1966), ISI Web of Knowledge (Science Citation Index Expanded, from 1985; Social Sciences Citation Index, from 1956; Arts \& Humanities Citation Index, from 1975), SportDiscus (from 1975) and IEEE Xplore was conducted at the last week of July in year 2010. The four databases were chosen as they were popular search engines which cover most of the literature in engineering, medicine and sports biomechanics field. The searched keyword string was "(biomechanics OR injury prevention OR kinematics) AND (lower limb OR knee OR hip 
OR ankle) AND (inertial sensor OR accelerometer OR gyroscope OR gyrometer OR magnetic sensor OR magnetrometer)" appeared in title, abstract, and keyword fields. The initial total number of identified articles from these databases was 195. Fifty four duplicated entries were moved, therefore 141 articles were left. Three articles not written in English were excluded, the number of articles were further reduced to 138. These 138 full papers were obtained from the library in The Chinese University of Hong Kong as well as from online search. The title and abstract of each entry was read, non-related studies were excluded, 36 full papers and conference abstract were left. Three more papers in related topic were added manually [9-11], therefore, a total of 39 full papers and conference abstract were included in this review. Inclusion criteria were as follow: (1) The study reported lower limb joint kinematics; and (2) The study involves accelerometers, gyroscopes and/or magnetic sensors. However, articles only contain the following content were excluded: (1) In vivo and in vitro kinematics studies; (2) Joint kinematics data not obtained from accelerometers, gyroscopes or magnetic sensors and (3) Frequency analysis.

Figure 1. Research method of this study.

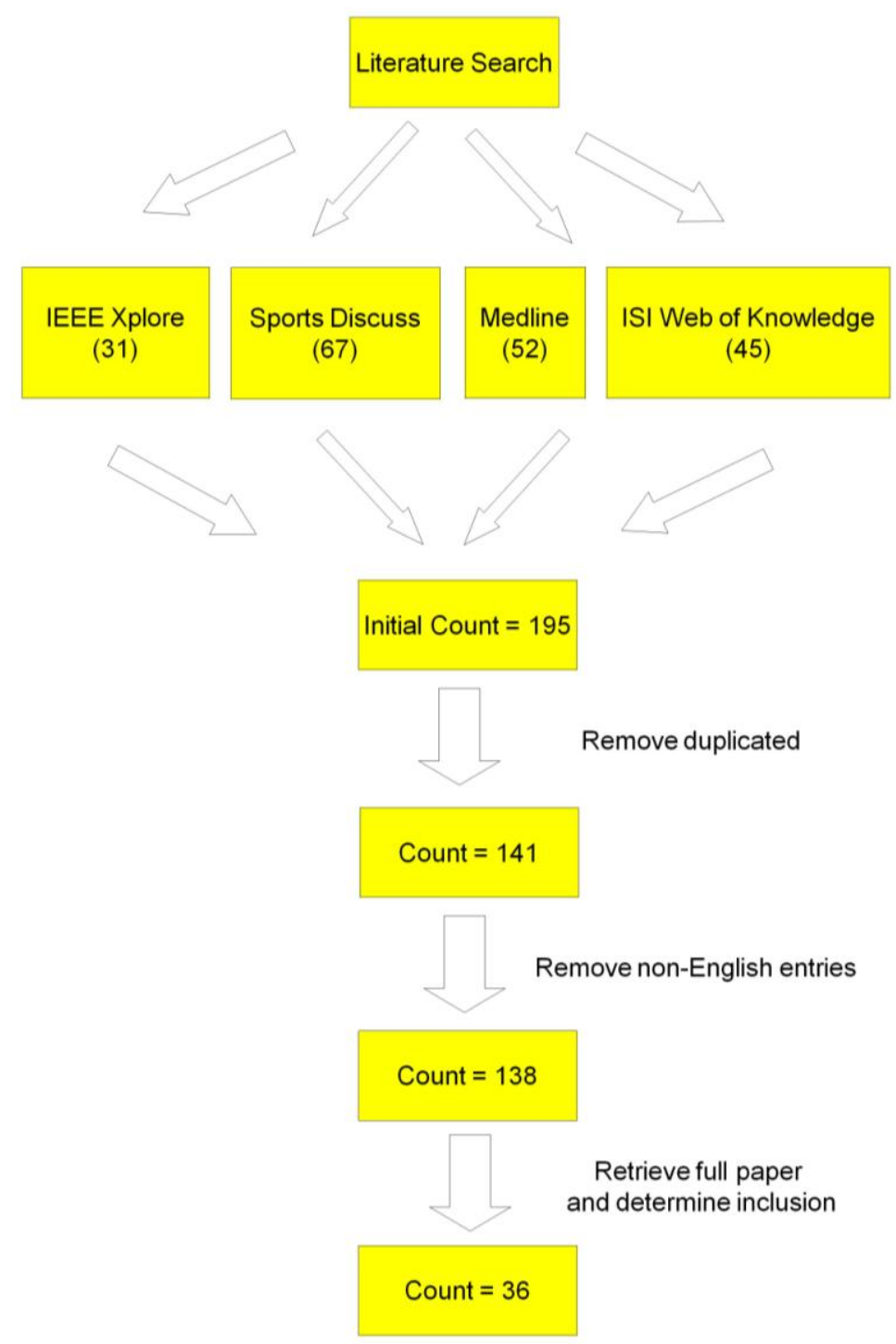




\section{Results and Discussion}

\subsection{Type of Sensors}

Type of sensors used ranged from uniaxial accelerometers to triaxial accelerometers, gyroscopes and magnetic sensor. Full scale of accelerometers ranged from $3 \mathrm{~g}$ to $10 \mathrm{~g}$, those of gyroscope ranged from 300-1,200 degree/second. For magnetic sensors, the full scale was 750 mGauss [12,13]. The weight of motion sensors adopted ranged from $18.2 \mathrm{~g}$ to $700 \mathrm{~g}$, and the size ranged from $20 \times 10 \times 7.2 \mathrm{~mm}^{3}$ to $64 \times 62 \times 26 \mathrm{~mm}^{3}$. Sampling frequencies of these systems ranged from $20-800 \mathrm{~Hz}$. Details of sensors used in the studies were shown in Table 1.

Table 1. Type of sensors adopted in reviewed studies.

\begin{tabular}{|c|c|c|c|c|c|c|c|}
\hline \multirow[b]{2}{*}{ Source } & \multirow{2}{*}{$\begin{array}{c}\text { Number } \\
\text { of sensor } \\
\text { module }\end{array}$} & \multicolumn{3}{|c|}{ Components of each sensor module } & \multirow[b]{2}{*}{ Sizes } & \multirow[b]{2}{*}{ Weight } & \multirow[b]{2}{*}{$\begin{array}{l}\text { Sampling } \\
\text { frequency }\end{array}$} \\
\hline & & Accelerometer & Gyroscope & $\begin{array}{c}\text { Magnetic } \\
\text { Sensor } \\
\end{array}$ & & & \\
\hline Cooper 2009 [1] & 1 & triaxial & triaxial & & & & $100 \mathrm{~Hz}$ \\
\hline Coley 2005 [2] & 1 & & uniaxial & & $30 \times 30 \times 30 \mathrm{~mm}^{3}$ & & \\
\hline Willemsen 1991 [3] & 16 & uniaxial & & & & & $500 \mathrm{~Hz}$ \\
\hline Heyn 1996 [4] & 8 & uniaxial & & & & & $100 \mathrm{~Hz}$ \\
\hline O'Donovan 2007 [6] & 2 & triaxial & triaxial & triaxial & $60 \times 40 \times 24 \mathrm{~mm}^{3}$ & & $500 \mathrm{~Hz}$ \\
\hline Favre 2008 [7] & 2 & triaxial & triaxial & triaxial & $30 \times 25 \times 25 \mathrm{~mm}^{3}$ & & $200 \mathrm{~Hz}$ \\
\hline Favre $2006[8]$ & 2 & triaxial & triaxial & triaxial & & & \\
\hline Cutti [9] & 10 & triaxial & triaxial & triaxial & $39 \times 54 \times 28 \mathrm{~mm}^{3}$ & $38 \mathrm{~g}$ & \\
\hline Van den Noort 2009 [11] & 2 & triaxial & triaxial & triaxial & & & $100 \mathrm{~Hz}$ \\
\hline Kawano 2007 [12] & 2 & triaxial & triaxial & triaxial & $53 \times 38 \times 21 \mathrm{~mm}^{3}$ & & $100 \mathrm{~Hz}$ \\
\hline Kawano 2008 [13] & 2 & triaxial & triaxial & triaxial & $53 \times 38 \times 21 \mathrm{~mm}^{3}$ & $30 \mathrm{~g}$ & $200 \mathrm{~Hz}$ \\
\hline Zijlstra 2008 [14] & 2 & triaxial & triaxial & & $64 \times 62 \times 26 \mathrm{~mm}^{3}$ & $150 \mathrm{~g}$ & \\
\hline Andrews 2000 [15] & 1 & uniaxial & & & & $18.2 \mathrm{~g}$ & \\
\hline Avor 2009 [16] & 4 & triaxial & triaxial & & & & \\
\hline Chan 2010 [17] & 1 & triaxial & triaxial & & $20 \times 18 \times 6 \mathrm{~mm}^{3}$ & & $500 \mathrm{~Hz}$ \\
\hline Dejnabadi 2005 [18] & 2 & biaxial & uniaxial & & $20 \times 20 \times 10 \mathrm{~mm}^{3}$ & & $200 \mathrm{~Hz}$ \\
\hline Dejnabadi 2006 [19] & 4 & biaxial & uniaxial & & $20 \times 20 \times 10 \mathrm{~mm}^{3}$ & & \\
\hline Ermes 2008 [20] & 3 & 2 triaxial & & 1 triaxial & & & $20 \mathrm{~Hz}$ \\
\hline Favre 2009 [21] & 2 & triaxial & triaxial & triaxial & & & $240 \mathrm{~Hz}$ \\
\hline Findlow 2008 [22] & 2 & triaxial & triaxial & & $54 \times 39 \times 28 \mathrm{~mm}^{3}$ & & \\
\hline Hanlon 2009 [23] & 2 & biaxial & & & & & $200 \mathrm{~Hz}$ \\
\hline Helot 2005 [24] & 2 & triaxial & & triaxial & & & $100 \mathrm{~Hz}$ \\
\hline Kendell 2009 [25] & 3 & triaxial & triaxial & triaxial & & & \\
\hline Lau 2009 [26] & 2 & biaxial & uniaxial & & $20 \times 10 \times 10 \mathrm{~mm}^{3}$ & & \\
\hline L'Hemette 2008 [27] & 1 & triaxial & & & & $700 \mathrm{~g}$ & $100 \mathrm{~Hz}$ \\
\hline Liu 2008 [28] & 2 & triaxial & & & & & \\
\hline Liu 2009 [29] & 3 & triaxial & & & & & \\
\hline Mamizuka 2007 [30] & 1 & triaxial & & & & & \\
\hline Mayagoitia 2002 [31] & 8 & uniaxial & & & & & $100 \mathrm{~Hz}$ \\
\hline Picemo [32] & 4 & triaxial & triaxial & triaxial & & & \\
\hline Saber-Sheikh 2010 [33] & 2 & triaxial & triaxial & triaxial & $53 \times 38 \times 21 \mathrm{~mm}^{3}$ & $30 \mathrm{~g}$ & \\
\hline Simcox 2005 [34] & 3 & 2 biaxial & 1 uniaxial & & $70 \times 50 \times 25 \mathrm{~mm}^{3}$ & & $800 \mathrm{~Hz}$ \\
\hline Tong 1999 [35] & 2 & & uniaxial & & $20 \times 10 \times 7.2 \mathrm{~mm}^{3}$ & & \\
\hline Willemsen 1990 [36] & 16 & uniaxial & & & & & $500 \mathrm{~Hz}$ \\
\hline Zhang 2008 [37] & 1 & biaxial & & & & & \\
\hline Ahmadi 2006 [38] & 3 & triaxial & & & & & $500 \mathrm{~Hz}$ \\
\hline Clark 2010 [39] & 1 & triaxial & & & & & \\
\hline
\end{tabular}




\subsection{Data Logging and Processing}

In most of the reviewed papers, collected data was not processed in a real time basis. Some of the systems have its own data logging system attached on the subject's body. Portable data loggers with different types of memory cards, for example, flash memories and SD-micro cards $[1,8,16,20,25,27,31]$ were one of the common methods for data logging. These memory cards allow handy data storage. There were also systems which required subjects to carry a hand held PC with them for data collection [34]. Hand held PC allows data collection in daily activities as they can be carried in pocket easily. However, their sizes were still not small enough for subjects performing vigorous sport motions. Wired systems which data were collected by a wired notebook PC also existed [17,30]. Bluetooth wireless communication was also adopted [9,33], which allows subjects to have more freedom of motion during data collection. However, workstation must present for data collection, therefore it is not suitable for ambulatory system.

One of the disadvantages of application of wearable sensors in human motion analysis was that noise in data collection was usually severe. Therefore, data have to be filtered before further processing. Low pass filters with cut off frequencies ranged from $15-40 \mathrm{~Hz}$ were adopted in various systems [2,3,6,26,29]. The cut off frequencies were chosen carefully based on the motions being performed. Butterworth filters [17,26], Kalman filters [1,10,37] and Savitzky-Golay filters [18,19] were also adopted in some other systems according to their applications and motions to be detected (Table 2). Curved fitting technique was also adopted to eliminate noise [33].

Table 2. Motions involved in reviewed studies.

\begin{tabular}{|l|l|}
\hline Source & Tested motions \\
\hline Cooper 2009 [1] & Walking at five speed from 1-5 mi/h \\
\hline Coley 2005 [2] & Walking, stair climbing \\
\hline Heyn 1996[4] & Walking \\
\hline O'Donovan 2007 [6] & $\begin{array}{l}\text { Heel and toe rise foot pumps, knee flexion and extension, clockwise } \\
\text { and anti-clockwise ankle rotation, lateral and medial foot rotation, } \\
\text { eversion and inversion, ambulation }\end{array}$ \\
\hline Favre 2008 [7] & Knee abduction and adduction, 30 m flat walking \\
\hline Favre 2006 [8] & Walking \\
\hline Cutti 2010 [9] & Walking \\
\hline Music 2008 [10] & Sit to stand movement \\
\hline Van den Noort 2009 [11] & Clinical assessment of knee joint \\
\hline Zijlstra 2008 [14] & Walking \\
\hline Andrews 2000 [15] & Landing from a 5 cm fall \\
\hline Avor 2009 [16] & Running on treadmill on three different speed \\
\hline Chan 2010 [17] & $\begin{array}{l}\text { Walking, running, jumping, walking downstairs, cutting, simulated } \\
\text { ankle sprain }\end{array}$ \\
\hline Dejnabadi 2005 [18] & Walking level at 3 km/h \\
\hline Ermes 2008 [20] & Walking, running, rowing, cycling \\
\hline Favre 2009 [21] & Walking \\
\hline Findlow 2008 [22] & Walking at self-selected pace \\
\hline
\end{tabular}


Table 2. Cont.

\begin{tabular}{|l|l|}
\hline Hanlon 2009 [23] & Walking \\
\hline Helot 2005 [24] & Walking \\
\hline Lau 2009 [26] & Walking level, upslope down slope, downstairs, upstairs \\
\hline L'Hemette 2008[27] & Walking \\
\hline Liu 2009 [29] & Walking at self-selected slow, normal and fast speeds \\
\hline Mamizuka 2007 [30] & Knee flexion and extension \\
\hline Mayagoitia 2002 [31] & Walking at $1.4 \mathrm{~km} / \mathrm{h}, 2.1 \mathrm{~km} / \mathrm{h}, 2.7 \mathrm{~km} / \mathrm{h}, 3.6 \mathrm{~km} / \mathrm{h}$ and $4.6 \mathrm{~km} / \mathrm{h}$ \\
\hline Picemo 2008 [32] & Walking \\
\hline Saber-Sheikh 2010 [33] & Walking \\
\hline Simcox 2005 [34] & Sit-stand-sit, walking \\
\hline Willemsen 1990 [36] & Walking \\
\hline Zhang 2008 [37] & Walking \\
\hline Ahmadi 2006 [38] & Tennis serving \\
\hline Clark 2010 [39] & Running on treadmill $(10 \mathrm{~km} / \mathrm{h})$ \\
\hline
\end{tabular}

\subsection{Study Design and Validation}

Most of the studies reviewed recruited young (age 18-40) healthy individuals as subjects. Only two studies have older subjects with average age of aged 58.7 [18,19]. Sample size ranged from one to 36. Walking and running on flat ground or treadmill were common motions being analyzed [1,2,4,8,14,16-18,21,22,24,27,29,31,34,36,37,39]. However, some other specific motions were also involved, for example, walking on difference surfaces [26], stand-sit transition [34], landing from a fall [15], tennis serve [38], rowing, cycling [20], jumping, walking downstairs, cutting, simulated sprain [17], walking upstairs [2], knee and ankle joint movement $[6,11,30]$.

The accuracies of the motion sensing systems were mostly compared with those of video cameras or high speed optical motion analysis systems with reflexive markers, as video cameras and optical motion analysis systems were commonly used for human joint kinematics assessment nowadays.

\subsection{Applications}

The reviewed papers monitored the joint kinematics of ankles, knees and hips. Most of the studies simplified these joints as simple hinge joints, which assume only sagittal plane movement was allowed. However, some studies could provide detailed three dimensional descriptions for ankle, knee and hip joints. Tibial acceleration was other commonly recorded parameters for human motion analysis. Tibial acceleration can be easily obtained from accelerometer data, without complicated data processing, therefore was favorable for real time monitoring and classification of different human activities.

By analysis of lower limb joint kinematics, several applications could be done, for example: Analysis of skill level and locomotor performance of athletes or patients [24,27,38]; ambulatory measurement to monitor patients' daily activities [7,816,29]; clinical assessment for patients [13,30]; 
Gait event detection and analysis [1,18,22,23,26,37,39] and identification of different daily activities, for example stair climbing, walking, running, rowing, cycling and simulated ankle sprain $[2,17,20]$.

\subsection{Fixation Methods}

Fixation methods were a very important part in motion analysis using motion sensors. A good fixation method reduced the artifices of skin movement. Moreover, good fixation methods can greatly reduced the errors caused by improper alignment to anatomical axes. Velcro straps [3,30], double-side adhesive tape [39], elastic straps [2,29,18,28] and neroprene straps [11] were commonly used for fixing motion sensors on subjects' bodies $[3,15]$. These tapes and straps are flexible and convenience to use. However, errors caused by skin movement can be significant. Some of the sensors were fixed on aluminum plate $[4,15,29,31,39]$ or put inside plastic casing [6,25] first before attaching on subject's bodies. Hard plate and casing can reduce relative skin movement and protect the sensors from damage. However, they are usually heavy and restrict subjects from normal movement. Semi-rigid belt [27] and exoskeleton [21] harness were also used for better sensor attachment, but are not convenience for long term ambulatory use. Another important note for fixation of sensor was that we have to ensure the axes of the inertial sensors aligned with the anatomical axes of the segments. Some studies applied anatomical calibration to align sensor's axes with the axes of the body segment. Calibration devices were adopted in static trial to identify the lines connecting anatomical landmarks [32]. Static postures were also adopted to calibrate the sensors in a functional approach [9].

\subsection{Discussion}

Some limitations still exist for lower limb human biomechanics analysis by wearable inertial motion sensors. Firstly, filtering, integration, trigonometry were involved to estimate joint angular kinematics. Therefore, high demand of hardware was needed for data processing, this made a higher cost and larger size for the data processing unit. Most importantly, complicated data processing technique means real time analysis nearly impossible in most of the studies. In some other studies, real time analysis was possible, for example Cutti [9] and his colleagues can measure real time joint kinematics, however, it was still limited to data collection in clinical setting.

Future development of joint kinematics analysis techniques for wearable inertial sensors should focus simplification of data processing algorithm would be the most challenging part. Batteries lives, fixation method, size of central processing unit were other aspects to be improved. Inertial sensors might replace video cameras and optical motion analysis systems in some human biomechanics studies as data collection could be done outside laboratory settings. The low cost of inertial sensors is obviously another advantage against optical motion analysis systems. Most importantly, it might be applied in ambulation system for real time motion classification, feedback to athletics about sports performance, monitor patients' daily activities and even act as alarm for activation of protective mechanism when the user was in danger of sports injury. 


\section{Conclusions}

Wearable inertial motion sensors are highly transportable and no stationary units, such as receivers and cameras are needed in data collection, therefore can be used outside laboratory conditions [2]. Due to the development of micro-electro-mechanical systems (MEMS), the size and power consumption were greatly improved in the design of sensor, making it a good choice for lower limb joint kinematics studies. However, data logging, data processing and fixation method are the areas to be improved in the near future. Simplify data processing algorithm can allow reduction of size and cost of the data processing unit, which allows easy attachment on users for ambulatory purpose. Fixation method which allows freedom of movement and minimizes skin movement is another important aspect.

\section{Acknowledgements}

This research project was made possible by resources donated by The Hong Kong Jockey Club Charities Trust.

\section{References}

1. Cooper, G.; Sheret, I.; McMillian, L.; Siliverdis, K.; Sha, N.; Hodgins, D.; Kenney, L.; Howard, D. Inertial sensor-based knee flexion/extension angle estimation. J. Biomech. 2009, 42, 2678-1685.

2. Coley, B.; Najafi, B.; Paraschiv-Ionescu, A.; Aminian, K. Stair climbing detection during daily physical activity using a miniature gyroscope. Gait Posture 2005, 22, 287-294.

3. Willemsen, A.T.M.; Frigo, C.; Boom, H.B.K. Lower extremity angle measurement with accelerometers-error and sensitivity analysis. IEEE Trans. Biomed. Eng. 1991, 38, 1186-1193.

4. Heyn, A.; Mayagoitia, R.E.; Nene, A.V.; Veltink, P. The kinematics of the swing phase obtained from accelerometer and gyroscope measurements. In Proceedings of 18th Annual International Conference of the IEEE Engineering in Medicine and Biology Society, Amsterdam, The Netherlands, 31 October-3 November 1996; pp. 463-464.

5. Morris, J.R.W. Accelerometry-A technique for the measurement of human body movements. J. Biomech. 1973, 6, 729-736.

6. O’Donovan, K.J.; Kamnik, R.; O’Keeffe, D.T.; Lyons, G.M. An inertial and magnetic sensor based technique for joint angle measurement. J. Biomech. 2007, 40, 2604-2611.

7. Favre, J.; Jolles, B.M.; Aissaoui, R.; Aminian, K. Ambulatory measurement of 3D knee joint angle. J. Biomech. 2008, 41, 1029-1035.

8. Favre, J.; Luthi, F.; Jolles, B.M.; Siegrist, O.; Najafi, B.; Aminian, K. A new ambulatory system for comparative evaluation of the three-dimensional knee kinematics, applied to anterior cruciate ligament injuries. Knee Surg. Sports Traumatol. Ar. 2006, 14, 592-604.

9. Cutti, A.G.; Ferrari, A.; Garofalo, P.; Raggi, M.; Cappello, A.; Ferrari, A. Outwalk: A protocol for clinical gait analysis based on inertial and magnetic sensors. Med. Biol. Eng. Comput. 2010, 48, $17-25$.

10. Music, J.; Kamnik, R.; Munih, M. Model based inertial sensing of human body motion kinematics in sit-to-stand movement. Simul. Model. Pract. Theory 2008, 16, 933-944. 
11. van den Noort, J.C.; Scholtes, V.A.; Harlaar, J. Evaluation of clinical spasticity assessment in Cerebral palsy using inertial sensors. Gait Posture 2009, 30, 138-143.

12. Kawano, K.; Kobashi, S.; Yagi, M.; Kondo, K.; Yoshiya, S.; Hata, T. Analyzing 3D knee kinematics using accelerometers, gyroscopes and magnetometers. In Proceedings of IEEE Conference on Systems Engineering 2007, San Antonio, TX, USA, 16-18 April 2007; pp. 1-6.

13. Kawano, K.; Kobashi, S.; Tsumori, Y.; Shibanuma, N.; Imawaki, S.; Yagi, M.; Yoshiya, S.; Hata, Y. Evaluation of pivot shift in the anterior cruciate ligament-injured knee using inertial and magnetic sensors. In Proceedings of Automation Congress, Waikoloa, HI, USA, 28 September2 October 2008; pp. 1-6.

14. Zijlstra, A.; Goosen, J.H.M.; Verheyen, C.C.P.M.; Zijlstra, W. A body-fixed-sensor based analysis of compensatory trunk movements during unconstrained walking. Gait Posture 2008, 27, 164-167.

15. Andrews, D.M.; Dowling, J.J. Mechanical modeling of tibial axial accelerations following impulsive heel impact. J. Appl. Biomech. 2000, 16, 276-288.

16. Avor, J.K. An approach to sensor fusion in medical robots. In Proceedings of IEEE 11th International Conference on Rehabilitation Robotics, Kyoto, Japan, 23-26 June 2009; pp. 818-822.

17. Chan, Y.Y.; Fong, D.T.P.; Chung, M.M.L.; Li, W.J.; Liao, W.H.; Yung, P.S.H.; Chan, K.M. Identification of ankle sprain motion from common sporting activities by dorsal foot kinematics data. J. Biomech. 2010, 43, 1965-1969.

18. Dejnabadi, H.; Jolles, B.M.; Aminian, K. A new approach to accurate measurement of uniaxial joint angles based on a combination of accelerometers and gyroscopes. IEEE Trans. Biomed. Eng. 2005, 52, 1478-1484.

19. Dejnabadi, H.; Jolles, B.M.; Casanova, E.; Fua, P. Estimation and visualization of sagittal kinematics of lower limbs orientation using body-fixed sensors. IEEE Trans. Biomed. Eng. 2006, 53, 1385-1393.

20. Ermes, M.; Pärkkä, J. Detection of daily activities and sports with wearable sensors in controlled and uncontrolled conditions. IEEE Trans. Inf. Technol. Biomed. 2008, 12, 20-26.

21. Favre, J.; Aissaoui, R.; Jolles, B.M.; de Guise, J.A.; Aminian, K. Functional calibration procedure for 3D knee joint angle description using inertial sensors. J. Biomech. 2009, 42, 2330-2335.

22. Findlow, A.; Goulermas, J.S.; Nester, C.; Howard, D.; Kenney, L.P.J. Predicting lower limb joint kinematics using wearable motion sensors. Gait Posture 2008, 28, 120-126.

23. Hanlon, M.; Anderson, R. Real-time gait event detection using wearable sensors. Gait Posture 2009, 30, 523-527.

24. Helot, R.; Pissard-Gibollet, R.; Espiau, B.; Favre-Reguillon, F. Continuous identification of gait phase for robotics and rehabilitation using microsensors. In Proceedings of IEEE 12th International Conference on Advanced Robotics, Seattle, WA, USA, 18-20 July 2005; pp. 686-691.

25. Kendell, C. Effect of mobility devices on orientation sensors that contain magnetometers. J. Rehabil. Res. Dev. 2009, 46, 957-962.

26. Lau, H.Y.; Tong, K.Y.; Zhu, H. Support vector machine for classification of walking conditions of persons after stroke with dropped foot. Hum. Movement Sci. 2009, 28, 504-514. 
27. L'Hemette, M.; Savatier, X.; Baudry, L.; Tourny-Chollet, C.; Dujardin, F. A new portable device for assessing locomotor performance. Int. J. Sports Med. 2008, 29, 322-326.

28. Liu, T.; Inoue, Y.; Shibata, K. Measurement of muscle motion for improving accuracy of body-mounted motion sensor. In Proceedings of IEEE/ASME International Conference on Advanced Intelligent Mechatronics, Xi'an, China, 2-5 July 2008; pp. 1325-1330.

29. Liu, K.; Liu, T.; Shibata, K.; Inoue, Y.; Zheng, R. Novel approach to ambulatory assessment of human segmental orientation on a wearable sensor system. J. Biomech. 2009, 42, 2747-2752.

30. Mamizuka, N.; Sakane, M.; Kaneoka, K.; Hori, N.; Ochiai, N. Kinematic quantitation of the patellar tendon reflex using a tri-axial accelerometer. J. Biomech. 2007, 40, 2107-2111.

31. Mayagoitia, R.E.; Nene, A.V.; Veltink, P.H. Accelerometer and rate gyroscope measurement of kinematics: An inexpensive alternative to optical motion analysis systems. J. Biomech. 2002, 35, 537-542.

32. Picermo, P.; Cereatti, A.; Cappozzo, A. Joint kinematics estimate using wearable inertial and magnetic sensing modules. Gait Posture 2008, 28, 588-595.

33. Saber-Sheikh, K.; Bryant, E.C.; Glazzard, C.; Hamel, A.; Lee, R.Y.W. Feasibility of using inertial sensors to assess human movement. Man. Ther. 2010, 15, 122-125.

34. Simcox, S.; Parker, S.; Davis, G.M.; Smith, R.W.; Middleton, J.W. Performance of orientation sensors for use with a functional electrical stimulation mobility system. J. Biomech. 2005, 38, 1185-1190.

35. Tong, K.; Granat, M.H. A practical gait analysis system using gyroscopes. Med. Eng. Phys. 1999, $21,87-94$.

36. Willemsen, A.T.; van Alste, J.A.; Boom, H.B. Real-time gait assessment utilizing a new way of accelerometry. J. Biomech. 1990, 23, 859-863.

37. Zhang, Z.; Wu, J.K.; Huang, Z. Gaussian particle filter for tracking hip angle in gait cycles. In Proceedings of 10th International Conference on e-health Networking, Applications and Services, 2008, Singapore, 7-9 July 2008; pp. 177-181.

38. Ahmadi, A.; Rowlands, D.D; James, D.A. Investigating the translational and rotational motion of the swing using accelerometers for athlete skill assessment. In Proceedings of 5th IEEE Conference on Sensors, Daegu, Korea, 22-25 October 2006; pp. 980-983.

39. Clark, R.A.; Bartold, S.; Bryant, A.L. Tibial acceleration variability during consecutive gait cycles is influenced by the menstrual cycle. Clin. Biomech. 2010, 25, 557-562.

(C) 2010 by the authors; licensee MDPI, Basel, Switzerland. This article is an open access article distributed under the terms and conditions of the Creative Commons Attribution license (http://creativecommons.org/licenses/by/3.0/). 